\title{
Identification of a novel antigen of pathogenic Leptospira spp. that reacted with convalescent mice sera
}

Correspondence

Haruo Watanabe

haruwata@nih.go.jp

Received 10 December 2002

Accepted 28 March 2003

\author{
Nobuo Koizumi and Haruo Watanabe
}

Department of Bacteriology, National Institute of Infectious Diseases, 1-23-1 Toyama, Shinjuku-ku, Tokyo 162-8640, Japan

\begin{abstract}
The virulence of leptospires isolated from human patients against $\mathrm{C} 3 \mathrm{H} / \mathrm{HeJ}$ mice was investigated. Infection with clinical isolates from patients with severe leptospirosis was lethal to $\mathrm{C} 3 \mathrm{H} / \mathrm{HeJ}$ mice, suggesting that $\mathrm{C} 3 \mathrm{H} / \mathrm{HeJ}$ mice are suitable as an acute lethal model of severe leptospirosis. Using this model, a novel antigen of pathogenic Leptospira spp. (named LAg42), which reacted with convalescent mice sera, was identified. LAg42 is a $42 \mathrm{kDa}$ inner-membrane protein and its immunogenic region is located in the C-terminal region. The gene for LAg42 is conserved among pathogenic leptospires but not among non-pathogenic leptospires, which suggests its involvement in virulence.
\end{abstract}

\section{INTRODUCTION}

Leptospirosis, caused by infection with pathogenic Leptospira spp., is an important zoonotic disease that is distributed worldwide. There are more than 230 serovars among the pathogenic leptospires (Faine et al., 1999); this diversity of serovars among leptospires is attributed to differences in LPS carbohydrate composition. Leptospiral LPS is a protective immunogen that is generally specific for each serovar (serogroup) (Faine et al., 1999). In contrast to LPS, however, protein extracts prepared from a pathogenic Leptospira isolate can induce protective immunity against challenge with a heterologous serovar in an experimental animal model (Sonrier et al., 2000). This result indicates that leptospiral proteins are potential candidates for a new vaccine that generates broad cross-protection beyond serovars. Identification of immunogenic proteins of leptospires has thus been attempted and some leptospiral proteins, such as LipL41, OmpL1 and Hap1 (also known as LipL32), are found to be protective immunogens that are conserved among pathogenic leptospires (Branger et al., 2001; Haake et al., 1999).

So far, laboratory guinea pigs and hamsters have usually been used as experimental animal models for leptospirosis. However, the high susceptibility of hamsters to highly virulent leptospire strains makes analyses difficult (Haake et al., 1999; this study). It has been reported that an inbred strain of mice

Abbreviations: IP, intraperitoneal; TLR, Toll-like receptor.

The GenBank/EMBL/DDBJ accession number for the nucleotide sequence of the lag 42 gene from L. interrogans serovar manilae strain UP$\mathrm{MMC}$ is $\mathrm{AB} 091092$.
$(\mathrm{C} 3 \mathrm{H} / \mathrm{HeJ})$, when infected with leptospires, exhibited histopathological lung and kidney changes that were similar to severe human leptospirosis (Pereira et al., 1998).

In this study, we aimed to confirm that $\mathrm{C} 3 \mathrm{H} / \mathrm{HeJ}$ mice are suitable as an acute lethal model of severe leptospirosis and to identify a novel antigen of pathogenic Leptospira spp.

\section{METHODS}

Animals. Female, specific pathogen-free $\mathrm{C} 3 \mathrm{H} / \mathrm{HeJ}$ mice and golden Syrian hamsters (SLC, Shizuoka, Japan) were used in this study. All animal experiments were approved by the animal research committee of the National Institute of Infectious Diseases (NIID).

Leptospira strains. Leptospira interrogans serovar manilae strain UPMMC was isolated from the blood of a human patient with severe leptospirosis at the University of Philippines in 1998 and was kindly provided by Dr Yanagihara. L. interrogans serovar icterohaemorrhagiae strain NIID-7 was isolated from the blood of a human patient, whose symptoms included jaundice and acute renal failure, at NIID in 2001. L. interrogans serovar hebdomadis strain OP84 was isolated from the blood of a human patient with mild leptospirosis at Okinawa Prefectural Institute of Health and Environment, Japan, in 1999 and was kindly provided by Dr Nakamura. To maintain virulence, leptospires were inoculated into hamsters, recovered from kidney tissues of dead or moribund hamsters and stored at $-80{ }^{\circ} \mathrm{C}$. Leptospira strains mentioned above and other reference strains were cultivated in liquid modified Korthof's medium with $10 \%$ rabbit serum at $30{ }^{\circ} \mathrm{C}$ (Faine et al., 1999).

Challenge experiments. Each Leptospira strain that had been passaged fewer than three times was used for intraperitoneal (IP) inoculation of mice or hamsters. The number of leptospires was counted by using a Thoma counting chamber (depth, $0.01 \mathrm{~mm}$ ) modified for darkfield microscopy. Nine-week-old mice and hamsters, in groups of five, were subjected to IP inoculation with a tenfold graded dose that ranged from $1 \times 10^{6}-10^{8}$ leptospires and with a 100 -fold graded dose that 
ranged from $1 \times 10^{1}-10^{7}$ leptospires, respectively. Liver and kidney tissues were removed from dead animals, minced and inoculated with Korthof s medium to demonstrate infection with leptospires. Mice that were still alive at 28 days after challenge were killed and their sera were harvested for subsequent experiments. Liver and kidney tissues were removed and inoculated into medium for the isolation of leptospires.

Isolation of genes that encode leptospiral protein antigens. Genomic DNA was prepared from L. interrogans serovar manilae strain UP-MMC using the cetyltrimethylammonium bromide (CTAB) precipitation method (Ausubel et al., 1993). The DNA was partially digested with Sau3AI, purified by sucrose gradient centrifugation and fragments that ranged from 2 to $6 \mathrm{kbp}$ were isolated and ligated to BamHI-digested ZAP Express vector (Stratagene). Escherichia coli XL-1 Blue $\mathrm{MRF}^{\prime}$ (Stratagene) was used as host strain to make a phage library. About $1 \times 10^{5}$ library clones were screened with the convalescent sera from mice that were still alive at 28 days after challenge and peroxidaseconjugated secondary antibody; positive clones were then detected using ECL Western blotting detection systems (Amersham Biosciences). A positive clone (IS44) was selected, plaque-purified and a plasmid (pBK-CMV; Stratagene) that contained insert DNA was autoexcised according to the supplier's instructions. Sequencing was performed by the dideoxynucleotide chain-termination method, using the BigDye Terminator Cycle Sequencing Ready Reaction kit, version 2.0 (Applied Biosystems).

SDS-PAGE and immunoblotting experiments. Samples were subjected to SDS-PAGE using the buffers described by Laemmli (1970) and Western blotting with the Tris/glycine/methanol buffer of Towbin et al. (1979). The blot was incubated in 900-fold-diluted convalescent mice sera or 10000 -fold-diluted anti-LAg42 serum and then detected as described above.

Expression and purification of recombinant LAg42 and 44-3/GST fusion proteins. The region of clone IS44 that encoded the mature part of the LAg42 protein was amplified with Taq DNA polymerase (Ex Taq, TaKaRa Biotech) by using the upstream primer LAg42-F (5' GGCGCGGATCCGTCCCGAAAAGGAGAGAAACG-3') and the downstream primer LAg42-R (5'-GGCCGCTCGAGCTATTCTCCCAACTCCTTGATG- $3^{\prime}$ ); the primers contained a BamHI site and an XhoI site, respectively, near their $5^{\prime}$ ends (underlined). After an initial $25 \mathrm{~s}$ denaturation step at $94^{\circ} \mathrm{C}$, the reaction mixture was subjected to 30 cycles of denaturation at $94{ }^{\circ} \mathrm{C}$ for $10 \mathrm{~s}$, annealing at $50{ }^{\circ} \mathrm{C}$ for $30 \mathrm{~s}$ and extension at $72{ }^{\circ} \mathrm{C}$ for $2 \mathrm{~min}$. DNA fragments corresponding to the $\mathrm{N}$ terminal $(\mathrm{LAg} 42 \mathrm{~N})$ and $\mathrm{C}$-terminal $(\mathrm{LAg} 42 \mathrm{C})$ of the $\mathrm{LAg} 42$ protein were amplified by using the upstream primer LAg42-F with the downstream primer LAg42-NR (5'-GGCCGCTCGAGCGAAGCGGTAGGACGAGTCAG-3'), and the upstream primer LAg42-CF (5'GGCGCGGATCCACTCCGGATAAAGGAGTCAG-3') with the downstream primer LAg42-R, respectively. A DNA fragment corresponding to the 44-3 protein was amplified by using the upstream primer $44-3 \mathrm{~F}$ (5'-GGCGCGGATCCCACACAGTCCATCATCAAGG- $3^{\prime}$ ) and the downstream primer T7 (5'-GTAATACGACTCACTATAGGGC-3'), located on pBK-CMV. Amplification conditions were identical to those described above except that the extension time was reduced to $1 \mathrm{~min}$. The PCR products were purified with a High Pure PCR Product Purification kit (Roche), digested with BamHI and XhoI (for LAg42, LAg42N and LAg42C) or BamHI only (for 44-3) and cloned into the GST vector pGEX-6P-1 (Amersham Biosciences). To express GST fusion proteins, the plasmids of GST/LAg42, GST/LAg42N, GST/ LAg42C and GST/44-3 fusion proteins were transformed into $E$. coli strain JM109. GST fusion proteins were expressed in E. coli JM109 clones that harboured each plasmid and purified using Glutathione Sepharose 4B (Amersham Biosciences), according to the supplier's instructions.
Production of anti-LAg42C serum. The LAg42C protein was cleaved from the GST/LAg42C fusion protein with PreScission protease (Amersham Biosciences) and purified according to the supplier's instructions. Antiserum against LAg42C was raised by intramuscular injection of $100 \mu \mathrm{g}$ purified LAg42C into a male Japan white rabbit (SLC, Shizuoka, Japan) with complete Freund's adjuvant, and giving booster injections of the same amount of protein with incomplete Freund's adjuvant 2 and 4 weeks later.

PCR. For amplification of the lag42 gene from various Leptospira strains, their genomic DNA was purified by using a High Pure PCR Template Purification kit (Roche). PCR was conducted with Ex Taq by using the upstream primer LAg42s-F (5'-ATCCCAAGCGCCTCTCGAAG- $3^{\prime}$ ) and the downstream primer LAg42-R under the conditions of an initial denaturation step at $94{ }^{\circ} \mathrm{C}$ for $25 \mathrm{~s}$, then 30 cycles of denaturation at $94{ }^{\circ} \mathrm{C}$ for $10 \mathrm{~s}$, annealing at $50{ }^{\circ} \mathrm{C}$ for $30 \mathrm{~s}$ and extension at $72{ }^{\circ} \mathrm{C}$ for $1 \mathrm{~min}$. Reference strains were obtained from Institut Pasteur, Paris, France (CZ 214 K, H 6, 1342 K, Veldrat Semarang 173, Celledoni and Jez Bratislava) and WHO, Geneva, Switzerland (Salinem, Veldrat Batavia 46, Castellon 3, Moskva V, 3522 C, Patoc I, CH 11, Hond Utrech IV, Pomona and Hardjoprajitno) and maintained at NIID. Other strains (Ictero No. 1, Akiyami A, Akiyami B, Akiyami C and Shibaura) had been isolated in Japan and maintained at NIID.

\section{RESULTS AND DISCUSSION}

\section{Animal models for infection with $L$. interrogans}

IP inoculation of $L$. interrogans serovar manilae strain UPMMC into 9-week-old hamsters resulted in a high percentage of lethal infection (Table 1). Although 3 of 20 hamsters survived to day 28 after the challenge, the time before death decreased as the challenge dose increased. The $50 \%$ lethal dose for strain UP-MMC given by IP inoculation in this experiment was $<10$ cells. Thus, hamsters are so susceptible to infection with a highly virulent Leptospira strain that it is difficult to analyse host immune responses against highly

Table 1. Virulence of L. interrogans strains UP-MMC and NIID-7 against experimental animals

\begin{tabular}{|c|c|c|c|c|}
\hline $\begin{array}{l}\text { Strain } \\
\left(\text { dose }^{\star}\right)\end{array}$ & Host & $\begin{array}{c}\text { No. } \\
\text { animals }\end{array}$ & $\begin{array}{c}\text { Survival } \\
\text { rate } \dagger\end{array}$ & $\begin{array}{l}\text { Time to death } \\
\text { (days) }\end{array}$ \\
\hline \multicolumn{5}{|c|}{ UP-MMC } \\
\hline $10^{7}$ & Syrian hamsters & 5 & 1 & $5,5,5,8$ \\
\hline $10^{5}$ & & 5 & 0 & $6,6,6,6,7$ \\
\hline $10^{3}$ & & 5 & 1 & $8,8,8,8$ \\
\hline $10^{1}$ & & 5 & 1 & $9,9,9,11$ \\
\hline $10^{8}$ & $\mathrm{C} 3 \mathrm{H} / \mathrm{HeJ}$ mice & 5 & 0 & $4,4,4,4,4$ \\
\hline $10^{7}$ & & 5 & 3 & 5,9 \\
\hline $10^{6}$ & & 5 & 5 & - \\
\hline \multicolumn{5}{|l|}{ NIID-7 } \\
\hline $10^{8}$ & $\mathrm{C} 3 \mathrm{H} / \mathrm{HeJ}$ mice & 3 & 0 & $4,4,6$ \\
\hline $10^{7}$ & & 3 & 0 & $9,9,10$ \\
\hline
\end{tabular}

${ }^{\star}$ Leptospires were inoculated into animals intraperitoneally.

$\dagger$ Number of animals that survived until day 28 . 
virulent Leptospira or the mechanism(s) of leptospiral pathogenesis. Thus, we tried to use mice as a model animal instead of hamsters. In 9-week-old $\mathrm{C} 3 \mathrm{H} / \mathrm{HeJ}$ mice, infection with $1 \times 10^{8}$ and $1 \times 10^{7}$ UP-MMC cells was 100 and $40 \%$ lethal, respectively (Table 1 ). The animals showed jaundice and subcutaneous haemorrhages; leptospires were recovered from liver and kidney tissues of dead animals. Another clinical isolate, L. interrogans NIID-7, isolated from a patient with severe leptospirosis, also showed lethal infection in $\mathrm{C} 3 \mathrm{H} / \mathrm{HeJ}$ mice (Table 1). However, L. interrogans OP-84, a clinical isolate from a patient with mild leptospirosis, did not kill any $\mathrm{C} 3 \mathrm{H} / \mathrm{HeJ}$ mice, even when $1 \times 10^{8}$ organisms were inoculated into 6-week-old mice (data not shown). Results obtained here and in a previous study (Pereira et al., 1998) indicate that $\mathrm{C} 3 \mathrm{H} / \mathrm{HeJ}$ mice are suitable animals for an acute lethal model of severe leptospirosis caused by highly virulent strains. $\mathrm{C} 3 \mathrm{H} / \mathrm{HeJ}$ mice possess a defective mutation in the gene encoding Toll-like receptor (TLR) 4, the inflammatory signalling receptor for LPS (Poltorak et al., 1998; Qureshi et al., 1999). $\mathrm{C} 3 \mathrm{H} / \mathrm{HeJ}$ mice are known to be highly resistant to LPS-induced shock but extremely susceptible to infection with the LPS-bearing pathogen Salmonella typhimurium (O'Brien et al., 1980). Leptospires produce an atypical LPS that differs from enterobacterial LPS in several biochemical, physiological and biological properties (de Souza \& Koury, 1992). A recent report demonstrated that leptospiral LPS activated target cells through a TLR2-dependent mechanism (Werts et al., 2001). Therefore, susceptibility of $\mathrm{C} 3 \mathrm{H} / \mathrm{HeJ}$ mice to leptospiral infection may not be attributed to TLR4; further study is required.

\section{Isolation of the leptospiral gene that encodes the LAg42 protein}

A leptospiral expression library from genomic DNA of $L$. interrogans serovar manilae strain UP-MMC was constructed and screened with convalescent sera from $\mathrm{C} 3 \mathrm{H} / \mathrm{HeJ}$ mice, as described above. A single clone (IS44) reacted positively; its plasmid DNA was purified and transformed into E. coli JM109. Immunoblot analysis (Fig. 1) showed that clone IS44 expressed a $42 \mathrm{kDa}$ protein that reacted with the convalescent mice sera [Fig. 1( $a$ and b), lane 1]. Sequence analysis of clone IS44 revealed that three open reading frames, genes 44-1, lag42 and 44-3, were encoded by the insert. 44-3 was fused to the C-terminal of lac $Z$ of the vector. Molecular masses of both the LAg42 and 44-3/LacZ fusion proteins were about $42 \mathrm{kDa}$. Therefore, in order to determine which protein reacted with the sera, GST/LAg42 and GST/44-3 fusion proteins were expressed in E. coli and probed with the convalescent sera. Both fusion proteins were expressed in E. coli but only the GST/LAg42 fusion protein reacted with the convalescent sera (Fig. 1a and b). Thus, the lag42 gene corresponds to the $42 \mathrm{kDa}$ protein that reacted with the convalescent sera. The LAg42 protein was also expressed in L. interrogans UP-MMC, with the same molecular mass (Fig. 1c).

The nucleotide and deduced amino acid sequences of the lag42 gene are available as supplementary data in JMM
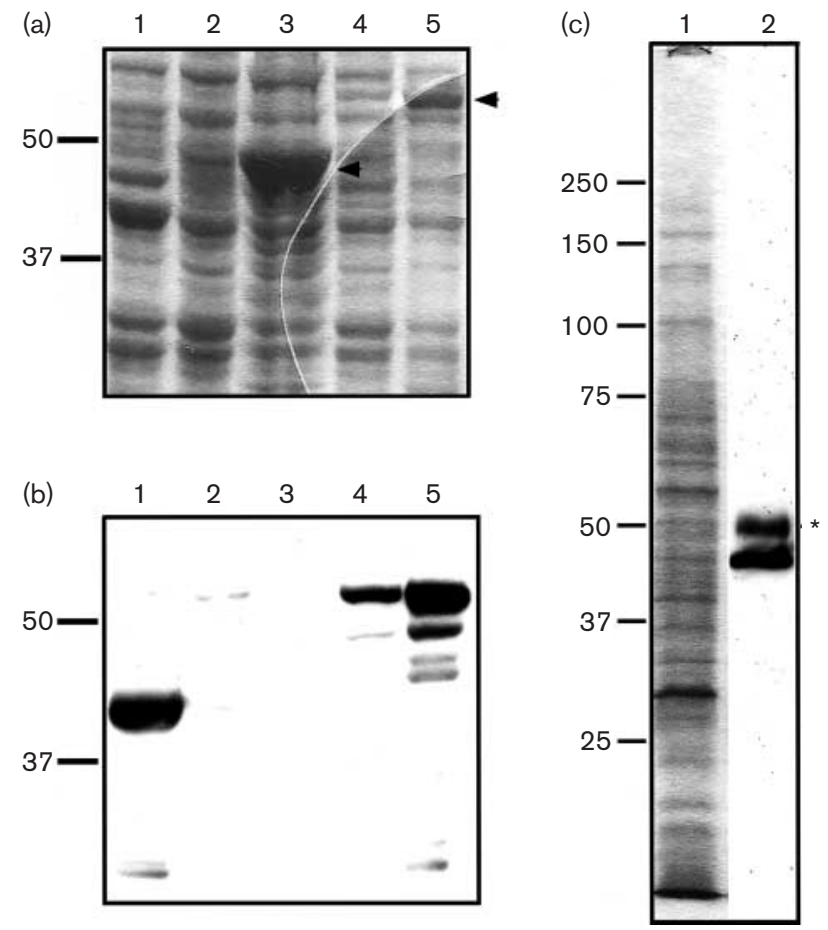

Fig. 1. Analysis of clone IS44 by (a) SDS-PAGE and (b) immunoblotting. E. coli JM109 harbouring clone IS44 or its derivatives was cultured overnight at $37^{\circ} \mathrm{C} ; 100 \mu \mathrm{l}$ was then transferred to $1 \mathrm{ml}$ fresh medium and cultured for a further $1 \mathrm{~h}$ at $37^{\circ} \mathrm{C}$. Then, $0.1 \mathrm{mM} \mathrm{IPTG}$ (final concn) was added to the culture, which was further incubated for $3 \mathrm{~h}$ at $37^{\circ} \mathrm{C}$. E. coli cells were pelleted and suspended in $100 \mu \mathrm{l} 1 \mathrm{X}$ SDS-PAGE sample buffer. Ten microlitres of the sample was subjected to SDS-PAGE and Western blotting with the convalescent mice sera. Lanes: 1, E. coli harbouring clone IS44; 2, E. coli harbouring the plasmid of GST/44-3, IPTG (-); 3, E. coli harbouring the plasmid of GST/44-3, IPTG (+); 4, E. coli harbouring the plasmid of GST/ LAg42, IPTG (-); 5, E. coli harbouring the plasmid of GST/LAg42, IPTG (+). Arrowheads indicate bands of each recombinant protein. (c) About $5 \times 10^{8}$ cells of $L$. interrogans strain UP-MMC were suspended in $100 \mu \mathrm{l} 1 \times$ SDS-PAGE sample buffer. Ten microlitres of the sample was subjected to SDS-PAGE and Western blotting with anti-LAg42C serum. Lanes: 1, SDS-PAGE; 2, immunoblotting. Asterisk indicates a non-specific band, which was detected with secondary antibody alone.

Online. We propose the TTG codon at positions 406-408, not the ATG codon at positions 562-564, as the translational start codon of LAg42, because a consensus -35 and -10 promoter element and a consensus ribosome-binding site were identified upstream of the predicted TTG start codon (see supplementary data in JMM Online). The predicted molecular mass (approx. $41537 \mathrm{Da}$ ) is also consistent with LAg42 expressed in L. interrogans UP-MMC (Fig. 1c). BLAST searches revealed that the N-terminal of LAg42 showed homology with the N-terminal of various hypothetical proteins in many pathogens, while the C-terminal of LAg42 did not significantly match any sequences in GenBank (data not shown). 


\section{LAg42 protein C-terminal is immunogenic}

Next, we tried to determine the immunogenic region in LAg42. The deduced amino acid sequence of LAg42 indicates that a transmembrane region is located at amino acid positions 107-123. Thus, we constructed GST fusion proteins with the $\mathrm{N}$-terminal (amino acid positions 1-95) and the C-terminal (amino acid positions 168-371) of LAg42 (see Methods) and performed immunoblot analysis. The result of the immunoblotting is shown in Fig. 2. The convalescent sera reacted with only the C-terminal of LAg42, which indicates that the C-terminal of LAg42 induces the production of antibodies in mice.

\section{Distribution of the lag42 gene among leptospires}

The presence of the lag42 gene among pathogenic and nonpathogenic leptospires was examined by PCR. A total of 18 Leptospira strains was evaluated. A PCR product of lag42 $(0.89 \mathrm{kbp})$ was amplified from all pathogenic leptospires tested, but not from non-pathogenic Leptospira biflexa or Leptospira meyeri (Fig. 3). We also revealed the presence of the lag42 gene in L. interrogans serovars bratislava (Jez Bratislava), canicola (Hond Utrech IV), pomona (Pomona) and hardjo (Hardjoprajitno) (data not shown). The absence of the lag42 gene in L. biflexa was proved by Southern blot analysis (data not shown).

The novel antigen LAg42 identified in this study does not appear to possess a signal sequence and has a transmembrane region, which suggests that this protein is an inner membrane protein with a molecular mass of $42 \mathrm{kDa}$. The C-terminal of

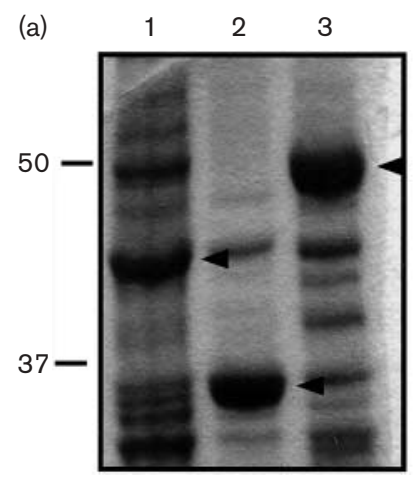

(b)

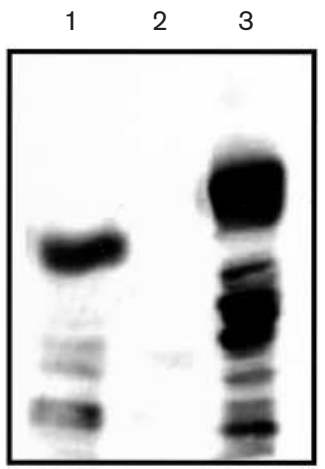

Fig. 2. Reactivity of convalescent mice sera to the $\mathrm{N}$ - and $\mathrm{C}$-terminals of the LAg42 protein. E. coli JM109 harbouring each plasmid was cultured overnight at $37^{\circ} \mathrm{C}$ and $100 \mu$ aliquots were transferred to $1 \mathrm{ml}$ fresh medium and cultured for $1 \mathrm{~h}$ at $37^{\circ} \mathrm{C}$. Then, $0.1 \mathrm{mM} \mathrm{IPTG}$ (final concn) was added to the culture, which was further incubated for $3 \mathrm{~h}$ at $37^{\circ} \mathrm{C}$. E. coli cells were pelleted and suspended in $100 \mu \mathrm{l} 1 \mathrm{X}$ SDS-PAGE sample buffer. Ten microlitres of each sample was subjected to (a) SDS-PAGE and (b) Western blotting with convalescent mice sera. Lanes: 1, E. coli harbouring clone IS44; 2, E. coli harbouring the plasmid of GST/LAg42N; 3, E. coli harbouring the plasmid of GST/LAg42C. Arrowheads indicate each recombinant protein.

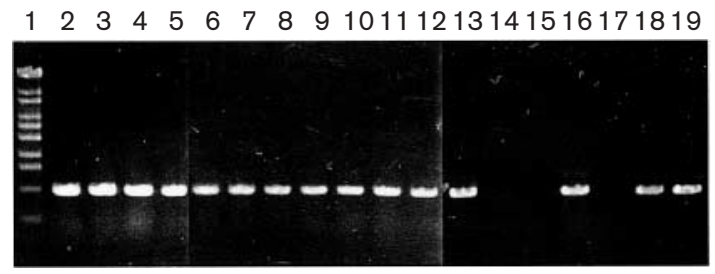

Fig. 3. Presence of the lag 42 gene among various leptospiral strains by PCR. Samples (amplified as described in Methods) were run on $0.9 \%$ agarose gel. Lanes: $1, \lambda$-EcoT14l digest; $2, L$. interrogans serovar icterohaemorrhagiae (Ictero No. 1); 3, L. interrogans autumnalis (Akiyami A); 4, L. interrogans hebdomadis (Akiyami B); 5, L. interrogans australis (Akiyami C); 6, L. interrogans pyrogenes (Salinem); 7, L. interrogans copenhageni (Shibaura); 8, Leptospira borgpetersenii javanica (Veldrat Batavia 46); 9, L. borgpetersenii castellonis (Castellon 3); 10, Leptospira kirschneri grippotyphosa (Moskva V); 11, L. kirschneri cynopteri (3522 C); 12, Leptospira noguchii panama (CZ $214 \mathrm{~K}) ; 13$, Leptospira inadai malaya (H 6); 14 , L. biflexa patoc (Patoc I); 15, L. biflexa andaman ( $\mathrm{CH} \mathrm{11);} \mathrm{16,}$ Leptospira santarosai shermani (1342 K); 17, L. meyeri semaranga (Veldrat Semarang 173); 18, Leptospira weilii celledoni (Celledoni); 19, L. interrogans manilae (UP-MMC).

LAg42 is immunogenic (Fig. 2), but does not show significant homology with any sequences in GenBank, whereas BLAST searches revealed that the $\mathrm{N}$-terminal of LAg 42 has similarity with the N-terminal of hypothetical proteins found in various pathogens. PCR results show that the lag 42 gene is conserved among pathogenic leptospires but not among non-pathogenic strains (Fig. 3). These results suggest that LAg42 may be involved in virulence and may also be a target for protective immune response. It has been demonstrated that whole protein extracts from a pathogenic Leptospira strain confer protection against homologous and heterologous challenge in an experimental animal model (Sonrier et al., 2000). Thus, the identification of protein antigens that are conserved among the pathogenic leptospires would lead to the development of new vaccines. OmpL1 and LipL41 have been shown to induce synergistic immunoprotection in hamsters (Haake et al., 1999). Adenovirus-mediated vaccination of Hap1 (also known as LipL32) induced protection in gerbils (Branger et al., 2001). The LAg42 protein may be one of the candidates for such new vaccines; however, further studies are required to evaluate its relevance.

\section{Conclusions}

In conclusion, we found that clinical isolates from patients who showed manifestations of severe, but not mild, leptospirosis produced lethal infection in $\mathrm{C} 3 \mathrm{H} / \mathrm{HeJ}$ mice. Our results and a previous report (Pereira et al., 1998) indicate that $\mathrm{C} 3 \mathrm{H} / \mathrm{HeJ}$ mice can be used as an acute lethal animal model of severe leptospirosis. By using convalescent sera from this animal model, we identified a novel antigen of pathogenic leptospires, designated LAg42. 


\section{ACKNOWLEDGEMENTS}

We are grateful to H. Kawabata for helpful suggestions throughout this study. We also thank Y. Yanagihara, G. Baranton and M. Nakamura for providing Leptospira strains. This work was supported by a grant from the Ministry of Health, Labour and Welfare (H12-Shinkou-29).

\section{REFERENCES}

Ausubel, F. M., Brent, R., Kingston, R. E., Moore, D. D., Seidman, J. G., Smith, J. A. \& Struhl, K. (editors) (1993). Current Protocols in Molecular Biology. New York: Wiley.

Branger, C., Sonrier, C., Chatrenet, B., Klonjkowski, B., RuvoenClouet, N., Aubert, A., André-Fontaine, G. \& Eloit, M. (2001). Identification of the hemolysis-associated protein 1 as a cross-protective immunogen of Leptospira interrogans by adenovirus-mediated vaccination. Infect Immun 69, 6831-6838.

de Souza, L. \& Koury, M. C. (1992). Isolation and biological activities of endotoxin from Leptospira interrogans. Can J Microbiol 38, 284-289.

Faine, S., Adler, B., Bolin, C. \& Perolat, P. (1999). Leptospira and Leptospirosis, 2nd edn. Melbourne, Australia: MediSci.

Haake, D. A., Mazel, M. K., McCoy, A. M., Milward, F., Chao, G., Matsunaga, J. \& Wagar, E. A. (1999). Leptospiral outer membrane proteins OmpL1 and LipL41 exhibit synergistic immunoprotection. Infect Immun 67, 6572-6582.

Laemmli, U. K. (1970). Cleavage of structural proteins during the assembly of the head of bacteriophage T4. Nature 227, 680-685.
O’Brien, A. D., Rosenstreich, D. L., Scher, I., Campbell, G. H., MacDermott, R. P. \& Formal, S. B. (1980). Genetic control of susceptibility to Salmonella typhimurium in mice: role of the LPS gene. J Immunol 124, 20-24.

Pereira, M. M., Andrade, J., Marchevsky, R. S. \& Ribeiro dos Santos, R. (1998). Morphological characterization of lung and kidney lesions in $\mathrm{C} 3 \mathrm{H} / \mathrm{HeJ}$ mice infected with Leptospira interrogans serovar icterohaemorrhagiae: defect of CD4+ and CD8+ T-cells are prognosticators of the disease progression. Exp Toxicol Pathol 50, 191-198.

Poltorak, A., He, X., Smirnova, I. \& 11 other authors (1998). Defective LPS signaling in $\mathrm{C} 3 \mathrm{H} / \mathrm{HeJ}$ and $\mathrm{C} 57 \mathrm{BL} / 10 \mathrm{ScCr}$ mice: mutations in Tlr4 gene. Science 282, 2085-2088.

Qureshi, S. T., Larivière, L., Leveque, G., Clermont, S., Moore, K. J., Gros, P. \& Malo, D. (1999). Endotoxin-tolerant mice have mutations in Toll-like receptor 4 (Tlr4). J Exp Med 189, 615-625.

Sonrier, C., Branger, C., Michel, V., Ruvoën-Clouet, N., Ganière, J. P. \& André-Fontaine, G. (2000). Evidence of cross-protection within Leptospira interrogans in an experimental model. Vaccine 19, 86-94.

Towbin, H., Staehelin, T. \& Gordon, J. (1979). Electrophoretic transfer of proteins from polyacrylamide gels to nitrocellulose sheets: procedure and some applications. Proc Natl Acad Sci U S A 76, 4350-4354.

Werts, C., Tapping, R. I., Mathison, J. C. \& 13 other authors (2001). Leptospiral lipopolysaccharide activates cells through a TLR2-dependent mechanism. Nat Immunol 2, 346-352. 